Introduction/Background To evaluate the role of transvaginal sonographic (tvUSG) endometrial thickness to detect endometrial cancers among postmenopausal women.

Methodology Endometrial biopsy results of 1099 postmenopausal patients who have been evaluated at our hospital since 2015 are retrospectively collected. Age, symptoms (asymptomatic vs. postmenopausal bleeding-PMB), tvUSG endometrial thickness were the parameters to be collected. Patients with insufficient endometrial sampling were excluded $(\mathrm{n}=103$,

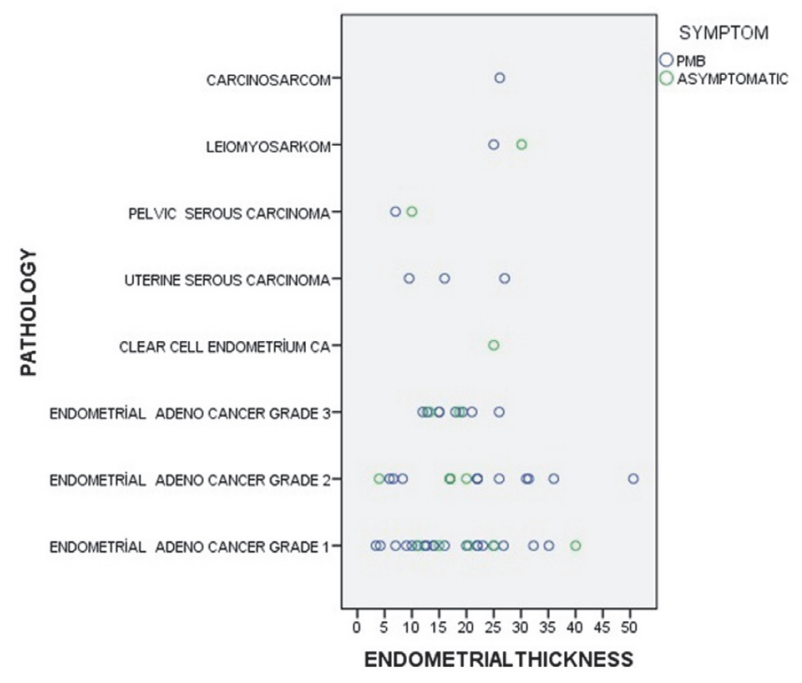

Abstract 357 Figure 1 Scatter plot graph comparing the endometrial pathologies vs. tvUSG thickness

\begin{tabular}{|c|c|c|c|}
\hline & $\begin{array}{l}\text { Patients with post-menopausal } \\
\text { bleeding } \\
(\mathbf{n}=(40) \\
n(9.6)\end{array}$ & $\begin{array}{c}\begin{array}{c}\text { Asymptomatic post- } \\
\text { menopausal patients } \\
(\mathrm{n}=356) \\
\mathrm{N}(96)\end{array} \\
\end{array}$ & $P$ Value \\
\hline \multicolumn{4}{|r|}{$<0.05$} \\
\hline 250 & $150(23.4)$ & $57(16)$ & \\
\hline 50.59 & $317(49.5)$ & $153(43)$ & \\
\hline $60-69$ & $107(16.7)$ & $107(30)$ & \\
\hline 570 & $66(10.3)$ & $39(11)$ & \\
\hline \multicolumn{3}{|l|}{ ENDOAETRIMI THCKNESS } & \multirow[t]{5}{*}{, 000} \\
\hline$\leq$ & $176(27.5)$ & $63(177)$ & \\
\hline $0-10$ & 251 (39.2) & $141(39.6)$ & \\
\hline 11-19 & $167(26.1)$ & $1199(33.4)$ & \\
\hline$\geq 20$ & $46(72)$ & $33(9.3)$ & \\
\hline \multicolumn{3}{|l|}{\begin{tabular}{|l} 
PATHOLOGY \\
\end{tabular}} & \multirow[t]{6}{*}{30.05} \\
\hline $\begin{array}{l}\text { BENGN/ PHYSTOLOOGICAL } \\
\text { ENDOMETRTUM(GROCPA) }\end{array}$ & $415(64.8)$ & $231(64.9)$ & \\
\hline ENDOMETRAAL POLYP (GROUP B) & $148(23.1)$ & $101(28.3)$ & \\
\hline $\begin{array}{l}\text { ENDOMETRIAL INTRAEPTTHELIAL } \\
\text { HYPERPLASIA (GROUPC) } \\
\end{array}$ & $28(4.3)$ & $9(2.5)$ & \\
\hline $\begin{array}{l}\text { ENDOMETRROID TYPE ENDOMETRtAL } \\
\text { CACNOOMA (OROUPD) }\end{array}$ & $40(6.2)$ & $11(3.0)$ & \\
\hline $\begin{array}{l}\text { NON-ENDOMEITRIOD TYPE } \\
\text { ENDOAETRAAL CACINOMA (GROUP E) }\end{array}$ & 9 (1.) & $4(1.3)$ & \\
\hline CANCER DETECTION & $49(7.9)$ & $15(4.2)$ & $<0.05$ \\
\hline \multicolumn{3}{|l|}{ TUMOR GRADE } & \multirow[t]{3}{*}{20.05} \\
\hline HIOH ORADE & $15(30,6)$ & 5(33.3) & \\
\hline LOW GRADE & $34(69.4)$ & $10(66.7)$ & \\
\hline
\end{tabular}

9.3\%). Remaining study group $(\mathrm{n}=996)$ were divided into 5 groups according to their histopathological diagnosis: benign/ physiological endometrium (group A), endometrial polyp (group B), endometrial hyperplasia or intraepithelial neoplasia (group C), endometrioid carcinoma (group D) and non-endometrioid carcinoma (group E). A scatter plot graph (figure 1) is prepared comparing the endometrial pathologies vs. tvUSG thickness.

Results A total of 996 endometrial biopsies were evaluated (356 patients were asymptomatic, 640 patients presented with postmenopausal bleeding). The median age of the patients was 57.3 years. The cancer detection rate among patients with bleeding was $7.6 \%$ (49/640). This rate was $4.2 \%$ in asymptomatic patients (15/356). The comparison of the two groups is presented in table 1 . High-grade cancers were detected three times more in symptomatic patients $(75 \%, 15 / 20$ vs. $25 \%, 5 / 20)$.

The mean endometrial thickness increases gradually from group A to group B: 8.3 for group A; and 12.1, 11.9, 18.7 and $16.0 \mathrm{~mm}$ for groups $\mathrm{B}, \mathrm{C}, \mathrm{D}$, and $\mathrm{E}$; respectively. In groups $\mathrm{D}$ and $\mathrm{E}$, there were only 4 patients with an endometrial thickness of less than $5 \mathrm{~mm}$ (6.2\%). Three patients were symptomatic and only one patient was asymptomatic.

A threshold of $5 \mathrm{~mm}$ can reveal $14 / 15$ cancers in asymptomatic patients, while this figure is $12 / 15$ for a $10 \mathrm{~mm}$ threshold and 6/15 for a threshold of 20 (figure 1). A threshold for $10 \mathrm{~mm}$ is reasonable for asymptomatic patients, missing 3 cancer patients (1 low grade, 2 high grade). In symptomatic patients, these figures were $46 / 49$ for $5 \mathrm{~mm}$ threshold (3 missed cancer), $37 / 49$ for a $10 \mathrm{~mm}$ threshold (12 missed cancer) and 21/49 for a $20 \mathrm{~mm}$ threshold (28 missed cancer).

Conclusion Endometrial biopsy should be performed routinely in patients with postmenopausal bleeding due to high numbers of missed cancers. However, in asymptomatic patients, a biopsy can safely be ignored in patients with endometrial thickness of less than $5 \mathrm{~mm}$. A biopsy may also be reserved for patients with an endometrial thickness $>10 \mathrm{~mm}$ (Cancer detection rate is $1.4 \%$ vs. $7.8 \%$ ).

Disclosures Nothing to declare.

\section{PHASE-SPECIFIC AND LIFETIME COSTS OF CERVICAL AND ENDOMETRIAL CANCER AMONG COMMERCIALLY INSURED PATIENTS IN THE UNITED STATES}

${ }^{1}$ Ruchitbhai Shah, ${ }^{1}$ Nehemiah Kebede, ${ }^{1}$ Anuj Shah, ${ }^{2}$ Shelby Corman, ${ }^{3}$ Chizoba Nwankwo. ${ }^{1}$ Pharmerit - an Open Health Company; Pharmerit International, Bethesda, MD, USA; ${ }^{2}$ Pharmerit; Pharmerit - an Open Health Company; USA; ${ }^{3}$ Merck and Co., Inc

\subsection{6/ijgc-2020-ESG0.70}

Introduction/Background There are little data describing the economic burden of cervical/endometrial cancers. Therefore, this study aimed to estimate the incremental lifetime economic burden among newly diagnosed cervical and endometrial cancer patients versus non-cancer controls using a phase-based costing approach.

Methodology Cervical and endometrial cancer patients newly diagnosed between January 2015 - June 2018, with continuous enrollment for 12 months prior and 6 months post diagnosis were identified in the Optum Clinformatics DataMart database. Non-cancer controls included patients who did not have any cancer diagnosis and had at least 18 months of continuous enrollment in the data. The index date was the date of the first diagnosis for cancer cases and the first claim date 


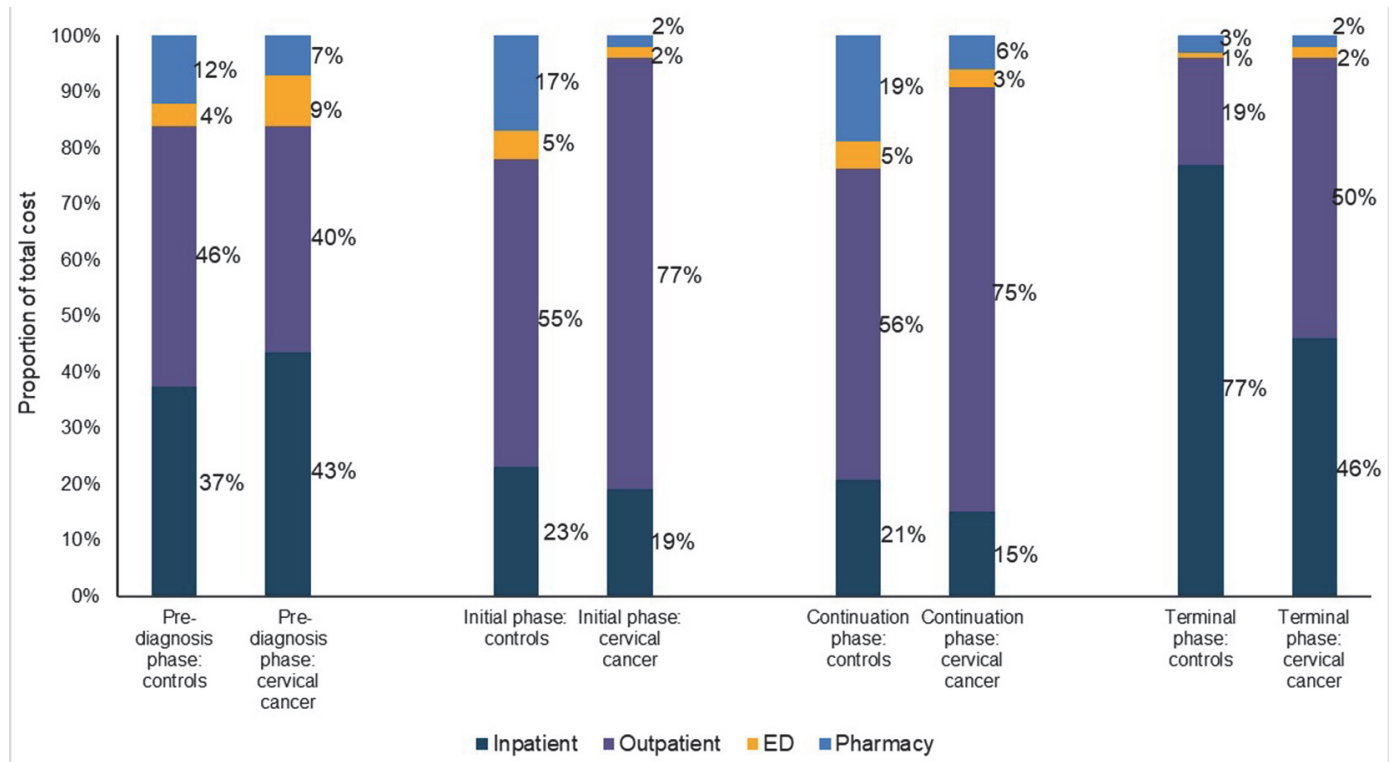

Abstract 362 Figure 1 Components of total costs by phase of care among cervical cancer patients and non-cancer controls

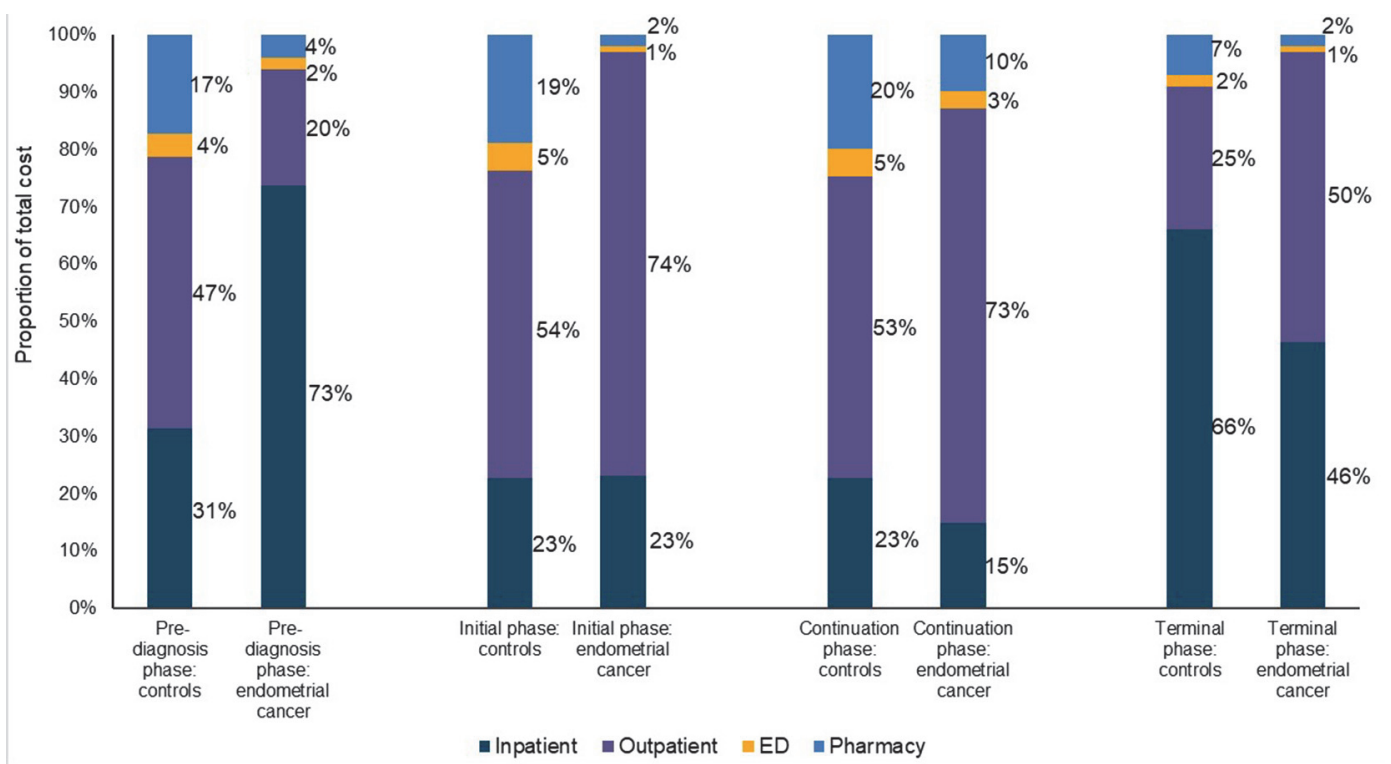

Abstract 362 Figure 2 Components of total costs by phase of care among endometrial cancer patients and non-cancer controls

after 12 months of continuous enrollment for non-cancer controls. Both cases and controls were followed until death/loss of enrollment/end of data availability. Cancer patients were matched with non-cancer controls on the propensity of receiving a cervical/endometrial cancer diagnosis, index year, and year of last follow-up.

Per patient per month (PPPM) costs (outpatient, inpatient, ER, pharmacy) attributable to cervical and endometrial cancer were calculated for the following 4 phases: pre-diagnosis (3 months prior to diagnosis), initial (6 months post-diagnosis), terminal (6 months pre-death), and continuation (any remaining time between initial and terminal phases). Survival data were obtained (cases: Surveillance, Epidemiology, and End Results registry; controls: United States life tables) to determine the monthly proportion of patients in each phase of care. Total survival adjusted monthly cost were obtained by multiplying the proportion of patients in each phase by the total cost incurred during that month (figures 1 and 2). Generalized linear models were used to assess phase-specific incremental costs attributable to cervical and endometrial cancer.

Results The analytic cohort included 1,002 cervical cancer patients and 4,005 matched non-cancer controls, and 5,003 endometrial cancer patients matched with 19,999 non-cancer controls. The incremental total PPPM phase-specific costs attributable to cervical and endometrial cancer were: pre-diagnosis (cervical: \$1,057; endometrial: \$3,315), initial (cervical: $\$ 12,084$; endometrial: $\$ 8,618$ ), continuation (cervical: $\$ 2,732$; endometrial: \$1,147), and terminal (cervical: \$2,702; endometrial: $\$ 5,442)$. Incremental costs were significantly higher for 
cancer patients versus non-cancer controls across all phases of care (except terminal phase costs for cervical cancer). Outpatient costs were the major driver of costs across all post-diagnosis phases (figure 1 and 2).

Conclusion The mean phase-specific costs followed the following order: Terminal $>$ Initial $>$ Continuation $>$ Pre-diagnosis. This study highlights the substantial cost burden associated with cervical/endometrial cancer, and cost variation by phases of care.

Disclosures This study was funded by Merck Sharp \& Dohme Corp., a subsidiary of Merck \& Co., Inc., Kenilworth, NJ, USA. Chizoba Nwankwo is an employee of Merck Sharp \& Dohme Corp., a subsidiary of Merck \& Co., Inc., Kenilworth, NJ, USA. Anuj Shah, Ruchit Shah, Shelby Corman, and Nehemiah Kebede are employees of Pharmerit International, which received consulting fees related to this study.
385 SAFETY AND ANTITUMOR ACTIVITY OF DOSTARLIMAB IN PATIENTS (PTS) WITH ADVANCED OR RECURRENT DNA MISMATCH REPAIR DEFICIENT (DMMR) OR PROFICIENT (MMRP) ENDOMETRIAL CANCER (EC): RESULTS FROM THE GARNET STUDY

${ }^{1}$ Ana Oaknin, ${ }^{2}$ Lucy Gilbert, ${ }^{3}$ Anna V Tinker, ${ }^{4}$ Renaud Sabatier, ${ }^{5}$ Valentina Boni, ${ }^{6}$ David M O'malley, ${ }^{7}$ Sharad Ghamande, ${ }^{8}$ Wei Guo, ${ }^{8}$ Ellie Im, ${ }^{9}$ Bhavana Pothuri. ${ }^{1}$ Vall D'hebron University Hospital, Vall D'hebron Institute of Oncology (Vhio); ${ }^{2}$ Mcgill University Health Centre-Ri; ${ }^{3} B C$ Cancer; ${ }^{4}$ Institut Paoli Calmettes, Aix-Marseille University; Department of Medical Oncology; ${ }^{5}$ Centro Integral Oncológico Clara Campal, Hospital Universitario Hm Sanchinarro; ${ }^{6}$ The Ohio State University - James CCC; ${ }^{7}$ Georgia Cancer Center, Augusta University; ${ }^{8}$ Glaxosmithkline; ${ }^{9}$ New York University; Department of Obstetrics and Gynecology

\subsection{6/ijgc-2020-ESGO.71}

Introduction/Background Dostarlimab is a humanised programmed death (PD)-1 receptor monoclonal antibody that

Abstract 385 Table 1 Antitumour activity

\begin{tabular}{|c|c|c|}
\hline Variable & dMMR EC, $n=103$ & MMRp EC, n=142 \\
\hline Median follow-up time, mo & 16.3 & 11.5 \\
\hline $\begin{array}{l}\text { Objective response rate*, n (\%, 95\% Cl) } \\
\text { Complete response, } \mathrm{n} \mathrm{( \% )} \\
\text { Partial response, } \mathrm{n}(\%) \\
\text { Stable disease, } \mathrm{n}(\%) \\
\text { Progressive disease, } \mathrm{n}(\%) \\
\text { Not evaluable, } \mathrm{n}(\%) \\
\text { Not done, } \mathrm{n}(\%)\end{array}$ & $\begin{array}{c}46(\mathbf{4 4 . 7 \% , 3 4 . 9 - 5 4 . 8 )} \\
11(10.7) \\
35(34.0) \\
13(12.6) \\
39(37.9) \\
3(2.9) \\
2(1.9) \\
\end{array}$ & $\begin{array}{c}19(13.4 \%, 8.3-20.1) \\
3(2.1) \\
16(11.3) \\
31(21.8) \\
77(54.2) \\
0 \\
15(10.6) \\
\end{array}$ \\
\hline Disease control rate ${ }^{\dagger}, \mathrm{n}(\%, 95 \% \mathrm{Cl})$ & $59(57.3 \%, 47.2-67.0)$ & $50(35.2 \%, 27.4-43.7)$ \\
\hline Response ongoing, $\mathbf{n}(\%)$ & $41(89.1)$ & $12(63.2)$ \\
\hline Median duration of response, (range) mo & Not reached (2.63-28.09+) & Not reached $(1.54+-30.36+)$ \\
\hline $\begin{array}{l}\text { Kaplan-Meier estimated probability of } \\
\text { remaining in response } \\
\text { at } 6 \mathrm{mo}, \% \\
\text { at } 12 \mathrm{mo} \% \\
\text { at } 18 \mathrm{mo} \%\end{array}$ & $\begin{array}{l}97.8 \\
90.6 \\
79.2 \\
\end{array}$ & $\begin{array}{l}83.0 \\
61.3 \\
61.3\end{array}$ \\
\hline
\end{tabular}

*Responses required confirmation at a subsequent scan; SD had to be observed at $\geq 12$ weeks on study to qualify as SD; †Includes confirmed CR, PR or SD at $\geq 12$ weeks.

$\mathrm{CR}$, complete response; $\mathrm{dMMR}$, mismatch mutation repair deficient; $\mathrm{EC}$, endometrial cancer; MMRp, mismatch mutation repair proficient, ORR, objective response rate; $P R$, partial response; SD, stable disease.

Abstract 385 Table 2 Most common adverse events

\begin{tabular}{|c|c|c|c|}
\hline MedDRA preferred term, $\mathrm{n}(\%)$ & $\begin{array}{c}\text { dMMR EC } \\
\mathrm{N}=126\end{array}$ & $\begin{array}{c}\text { MMRp EC } \\
\mathrm{N}=145\end{array}$ & $\begin{array}{l}\text { Overall } \\
\mathrm{N}=271\end{array}$ \\
\hline \multicolumn{4}{|l|}{ Any grade TRAEs } \\
\hline Fatigue & $17(13.5)$ & $30(20.7)$ & $47(17.3)$ \\
\hline Diarrhoea & $20(15.9)$ & $19(13.1)$ & $39(14.4)$ \\
\hline Nausea & $16(12.7)$ & $21(14.5)$ & $37(13.7)$ \\
\hline \multicolumn{4}{|l|}{ Grade $\geq 3$ TRAEs } \\
\hline Anaemia & $5(4.0)$ & $2(1.4)$ & $7(2.6)$ \\
\hline $\begin{array}{l}\text { Alanine aminotransferase } \\
\text { increased }\end{array}$ & $2(1.6)$ & $2(1.4)$ & $4(1.5)$ \\
\hline Diarrhoea & $2(1.6)$ & $2(1.4)$ & $4(1.5)$ \\
\hline \multicolumn{4}{|l|}{ TRAEs leading to discontinuation } \\
\hline $\begin{array}{l}\text { Alanine aminotransferase } \\
\text { increased }\end{array}$ & $1(0.8)$ & $2(1.4)$ & $3(1.1)$ \\
\hline $\begin{array}{l}\text { Aspartate aminotransferase } \\
\text { increased }\end{array}$ & $1(0.8)$ & $1(0.7)$ & $2(0.7)$ \\
\hline Transaminases increased & $2(1.6)$ & 0 & $2(0.7)$ \\
\hline
\end{tabular}

dMMR, mismatch mutation repair deficient; EC, endometrial cancer; MMRp, mismatch mutation repair proficient; TRAE, treatment-related adverse event. 